\title{
Implications of integrating safety and social responsibility in selected construction companies in Nigeria
}

\author{
Dr. M.O. Agwu, MNIM, MNISP \\ Department of Business Administration, Niger Delta University, Wilberforce Island, \\ Bayelsa State
}

\begin{abstract}
The paper focuses on the implications of integrating safety and social responsibility initiatives at the organizational level in five selected construction companies in Nigeria. The research question addressed the extent to which integration of safety and social responsibility is dependent on the safety management system and its implications on improved corporate performance (improved productivity, good corporate governance, improved stakeholders relations and reduced accident/incident rate) in the selected construction companies. It assumes that the practice of safety in Nigerian construction companies must move beyond the mere business aspects of safety and focus on how safety management demonstrates good corporate governance and social responsibility by promoting benefits and values that address all stakeholders in the construction industry. An exploratory cross-sectional survey research design was used in conducting the study using questionnaire administered on 396 randomly selected respondents from the five selected construction companies. The questionnaire responses were presented using tables, analyzed using simple percentages while formulated hypotheses were tested using chi-square $\left(x^{2}\right)$. The results indicated that integration of safety and social responsibility is to a large extent dependent on the safety management system and better corporate performance (improved productivity, good corporate governance, and improved stakeholders' relations and reduced accident/incident rate) is to a large extent dependent on the integration of safety and social responsibility. The study concludes that integrating safety and social responsibility in construction activities results in better corporate performance. The study therefore recommends among others adoption of a systems approach to safety management that links safety and social responsibility in construction companies using ISO 26000 , holding top management accountable for safety and communicating safety value to corporate stakeholders.
\end{abstract}

Keywords: safety, safety management, social responsibility, corporate performance, organizational level.

\section{INTRODUCTION}

Effective safety management system in the construction industry requires the attention and support of decision makers in upper management. According to Adams (2003), the safety professional's main responsibility is to seek "active support for safety function affairs from higher level management." Speaking the language of business requires knowledge of business and financial skills combined with an understanding of the stakeholders the business serves. In the construction industry environment, decision makers have many obvious and not so obvious stakeholders to serve. The main stakeholder traditionally served is the shareholder or investor seeking a return on investment. The safety profession has recognized that to gain the attention of corporate decision makers its practitioners must be able to justify expenditures and present safety in terms of its positive impact on bottom-line profits as a return on investment (Schneid, 2008). However, the value safety brings to an organization goes beyond the financial statement.

Construction companies in Nigeria owe ethical responsibilities to all stakeholders in the construction industry, not just investors or financial supporters. Safety professionals can promote the value of safety by demonstrating how effective safety management system serves all of an organization's stakeholders. This paper explores how safety can be integrated into social responsibility and sustainability initiatives in the attainment of better organizational performance (improved productivity, good corporate governance, and improved stakeholders' relations and reduced accident/incident rate). To achieve this, safety 
professionals must think in terms of creating and sustaining value for key stakeholders, no matter the business's overall purpose or direction (Freeman, Harrison \& Wicks, 2007). The profession must move beyond the mere business aspects of safety and focus on how safety management demonstrates good corporate governance and social responsibility.

Safety professionals in the construction industry may be good at managing safety programs, but not always successful at demonstrating how they contribute to profits. On the other hand, construction companies may effectively manage profits, but may not be so good at demonstrating commitment to safety programs. The ability of construction companies and their shareholders to focus purely on profit has limits under the new global framework of good corporate governance and social responsibility initiatives. Hence, today's safety professionals must recognize this transformation in the global construction industry and seize the opportunity to expand the role of safety professionals within the organization's governance system, so as to be seen as value-added employees by decision makers and the stakeholders they serve. This can be achieved by demonstrating the ability to promote people (safety and health), the planet (environment) and profits (value-add).

Safety professionals in the construction industry must recognize their corporate decision makers as well as their stakeholders. The range of stakeholders has expanded over the years from owners or shareholders to a broader group that now includes those who affect or are affected by a firm's goals (Freeman, et al., 2007) or who have a stake in a firm's operations (Werther \& Chandler, 2006). This group includes customers, suppliers, employees, financiers, communities and managers (Freeman, et al.). Thus, effective construction safety management must promote benefits and values that address all construction industry stakeholders. This will ensure that safety professionals are better recognized, understood and appreciated by decision makers within the construction industry. Hence, safety professionals must play a vital role in teaching and educating decision makers and stakeholders about the "importance and beneficial aspects of safety in their operations" (Schneid, 2008). Beyond the effect on profits, construction safety professionals must design safety management programs that address the needs of stockholders and stakeholders.
Systems Approach Helps Link Safety to Social Responsibility: Internationally, the systems approach to safety management was promulgated by the adoption of ISO 9001, Quality Management Systems, and ISO 14001, Environmental Management Systems. In the past two decades, its standards/programs have increasingly served as a consistent framework for linking safety to social responsibility.

Using ISO 26000 to Link Safety \& Social Responsibility: ISO 26000 outlines principles for recognizing social responsibility efforts and engaging stakeholders through the following: Recognizing unique needs of members, Employee participation in safety, Safety committee guidelines, Eliminate workplace hazards, Two-Way communication on safety, Worker safety training, Worker input on the economics of safety, Safety in the value chain and Personal protective equipment. Construction safety professionals can use the ISO 26000 standard's structure to demonstrate the strategic role safety management plays in social responsibility.

Recognizing Unique Needs of Members of the Organization: Safety management often involves addressing the unique issues related to ergonomics, disabled workers, language barriers, cultural differences, young workers and an aging workforce. Safety professionals should highlight these programs when demonstrating organizations' social responsibility efforts toward recognizing the unique needs of its workforce.

Employee Participation in Safety Efforts: Several safety management systems in construction companies highlight the need for employee participation. Employee participation can take many forms:

* Participate on joint labor-management committees and other advisory or specific purpose committees.

* Conduct site inspections.

* Analyze routine hazards in each step of a job or process, and prepare safe work practices or controls to eliminate or reduce exposure.

* Develop and revise site safety and health rules.

* Train both current and newly hired employees.

* Provide programs and presentations at safety and health meetings.

* Conduct incident investigations. 
* Report hazards and fixing those in their control.

* Support co-workers by providing feedback on risks and helping them eliminate hazards.

Guidelines for Safety Committee Development: Active safety committees are another way to demonstrate direct employee involvement while also satisfying another component of good social responsibility. Safety committees are voluntary in many organizations but may be required by company policy or local regulations. The key is that workers must have a true voice on the committee.

Efforts to Eliminate Workplace Psychosocial Issues: Psychosocial issues can include stress, posttraumatic stress, workplace violence, bullying, substance abuse, absenteeism, racism and racial/ethnic prejudice, sexism and sexual harassment, gender and racial discrimination, workfamily integration and balance, and support for diversity in the workplace/workforce. Safety professionals may be directly or indirectly involved with one or more psychosocial programs within their organizations, but all safety programs must address hazard identification and abatement methodologies that can be correlated to sound socially responsible actions.

Two-Way Safety Communication: Sound safety management requires commitment of all levels of an organization, particularly top management. Management leadership and employee involvement go hand in hand for safety success. In fact, top management leadership and effective employee participation are crucial for the success of a safety management system. Managers organize and control activities within an organization. They provide the motivating force, resources and influence necessary for safety to be a fundamental value within the organization. In an effective program, management involvement also provides the means through which workers express their own commitment to safety and health for themselves and their fellow workers (OSHA, 1989). The next step is to establish communication and trust between management and workers.

Safety Culture \& Social Responsibility: According to Manuele (2003), an organization's culture consists of its values, beliefs, legends, rituals, missions, goals and performance measures, and its sense of responsibility to its employees, its customers and its community, all of which translate into a system of expected behavior. An organization's culture dictates the effectiveness of a safety management system. Petersen (2003) found that an organization's culture sets the tone for safety as well. "In a positive safety culture, it says that everything you do about safety is important". Consider this statement by OSHA: "The best safety and health programs involve every level of the organization, instilling a safety culture that reduces accidents for workers and improves the bottom line for managers. When safety and health are part of the organization and a way of life, everyone wins" (OSHA, 2002).

Worker Safety Training: In 1986, OSHA issued a program evaluation profile for compliance officers to use when evaluating a site's safety program. Although this directive was eventually rescinded, it serves as guidance in evaluating a sound employee training program. Guidelines from this document include the following:

$>$ Knowledgeable persons conduct safety and health training.

$>$ Training is properly scheduled, assessed and documented.

$>$ Training covers all necessary topics and situations, and includes all persons working at the site.

$>$ Employees participate in creating sitespecific training methods and materials.

$>$ Employees are trained to recognize inadequate responses to reported program violations.

$>$ A retrievable recordkeeping system provides for appropriate retraining, makeup training and

$>$ Modifications based on evaluations.

These guidelines also provide employers with instructions needed for employees to work at minimal risk to themselves, fellow employees and the public. These guidelines include the following(1) Determine whether a worksite problem can be solved by training,(2) Determine what training, if any, is needed,(3) Identify goals and objectives for the training,(4) Design learning activities,(5) Conduct training,(6) Determine the effectiveness of the training and(7) Revise training based on feedback from employees, supervisors and other workers.

Workers' Rights Regarding the Economics of Safety: Social responsibility requires a balance between people, profits and the planet. Social responsibility should affect the balance on economic decisions with issues related to worker safety and health from the perspective of the workforce. This 
starts with safety professionals linking safety initiatives with profits or demonstrating the business of safety. Construction companies and their stakeholders may see additional benefits of implementing safety programs beyond the reduction of injury and illnesses. Some of these benefits may include: lowered workers' compensation costs, reduced turnover of personnel, reduced lost workdays, compliance with laws and regulations, increased productivity, improved employee health status, improved product quality, higher morale of employees, reduction or elimination of property damage due to incidents, reduced business interruption costs, and reduced impact on the environment due to incidents. These are the positive benefits of an effective safety management system that senior management can see. Construction safety professionals must paint the picture of success and obtain management's commitment while the vision is fresh. A little salesmanship can integrate safety into the business model by illustrating incident and accident effects on production and profitability. Integrating the costs of safety into the business and demonstrating a return on investment has been identified as a major goal of the safety profession. This puts safety into a language that management, frontline supervisors and even employees can understand. However, when a safety initiative has a negative impact on the bottom line, it may lose priority. Socially responsible organizations will weigh the benefits of a safety initiative based on its social and environment impacts as well as its effect on corporate profits. Active safety programs that routinely involve employees in reducing workplace hazards should be highlighted as an example of meeting this social responsibility initiative.

Safety in an Organization's Value Chain: ISO 26000 defines value chain as entire sequences of activities or parties that provide (suppliers, outsourced workers, contractors) or receive (customers, consumers, clients, members and other users) value in the form of products or services. Organizations have found that sustainability can be reached only through people (Nestle, 2009). No asset is as important as the people who contribute to organizational culture and goals through their work. These organizations devote all the necessary energy and attention to protect employees, contractors and others along the value chain, including suppliers, customers and the public. Construction companies can highlight social responsibility by requiring suppliers to meet minimum safety program requirements. This can include the procurement of products and services with reduced environmental impact (i.e., a green supply chain). Also construction companies can mandate compliance to standards higher than what is mandated by local regulations and audit their supply chain's safety commitment.

Personal Protective Equipment: PPE use is an important aspect of social responsibility obligations. However, regulations and best practices require construction companies to address workplace hazards using a hierarchy of controls. PPE must be used a last resort to protect workers. It is acceptable as a hazard control method under the following circumstances:

$\checkmark \quad$ when engineering controls are not feasible or do not totally eliminate the hazard;

$\checkmark$ while engineering controls are being developed;

$\checkmark$ when safe work practices do not provide sufficient additional protection;

$\checkmark$ during emergencies when engineering controls may not be feasible.

Construction companies should implement and maintain a process for achieving feasible risk reduction based on the following preferred order of controls: elimination; substitution of less hazardous materials, processes, operations or equipment; engineering controls; warnings; administrative control; and PPE.

Feasible application of this hierarchy of controls shall take into account:

$>$ the nature and extent of the risks being controlled;

$>$ the degree of risk reduction desired;

> the requirements of applicable local, federal and state statutes, standards and regulations; recognized best practices in industry;

$>$ available technology;

$>$ cost-effectiveness;

> Internal organization standards.

Effective social responsibility will look well beyond providing PPE and incorporate the hierarchy of controls into hazard reduction activities.

Research Objectives: The objective of this research is to ascertain the extent to which integration of safety and social responsibility is dependent on the safety management system and its implications on better corporate performance (improved productivity, good corporate governance, improved stakeholders relations and reduced accident/incident rate) in the 
five selected construction companies in Nigeria. Since there is support in the literature for the argument that integrating safety and social responsibility in an organization's safety management system not only addresses risk management and legal compliance, it also includes innovation and opportunities that benefit all stakeholders.

Research Questions: With increasing globalization, greater environmental and social awareness, and more efficient communication, the Nigerian construction industry must expand the role of safety professionals within the organization's governance system, so as to be seen as value-added employees by decision makers and the stakeholders they serve. This identified future role of safety professionals in Nigeria's construction industry has prompted the following research questions:

1. To what extent is integration of safety and social responsibility dependent on the safety management system in the five selected construction companies?

2. To what extent is better corporate performance (improved productivity, good corporate governance, improved stakeholders relations and reduced accident/incident rate) dependent on the integration of safety and social responsibility in the five selected construction companies?

Research Hypotheses: In view of the above research questions, the following null hypotheses were formulated to aid the study:

1. The integration of safety and social responsibility is not dependent on the safety management system in the five selected construction companies.

2. Better corporate performance (improved productivity, good corporate governance, improved stakeholders relations and reduced accident/incident rate) is not dependent on the integration of safety and social responsibility in the five selected construction companies.

\section{Conceptual and Theoretical Framework}

Conceptual Framework: In the construction industry, safety management system is viewed as a quality management system designed for managing risks within the company, so as to ensure the protection of people, assets, reputation and the environment from the hazards of construction activities. Thus effective safety management system must also promote the value of safety to all stakeholders by integrating safety and social responsibility in the execution of construction activities.

From the perspective of stakeholders, safety professionals in the Nigerian construction industry can get managers to listen - to understand that safety professionals are not technicians, regulatory compliance specialists or "necessary evils," but welleducated professionals who are concerned with promoting the cost-effective use of organizational resources to immediately affect the bottom line (Adams, 2003).

Globally the construction industry is changing hence the means and methodologies through which safety professionals accomplished safety management objectives in the past may not work in the future. Today's construction safety professionals must adapt new thinking and anticipate major changes within the profession in the near future (Schneid, 2000).In addition, safety professionals in the construction industry will have an increased role in developing internal programs that integrates safety and social responsibility to ensure the reliable flow of safety information to corporate decision makers and boards of directors (Hall, 2003). Organizations in the construction industry now realize that good governance founded on a strong ethical climate that integrates safety and social responsibility represents a best business practice (Verschoor, 2007). Construction safety professionals must incorporate this good governance practice into their safety management system so that safety best practices become how good business is conducted in the construction industry.

Theoretical Framework: This research is based on Freeman's (1984) stakeholder theory which defines stakeholders as any group or individual who can affect or is affected by the achievement of the firm's objectives hence the firm has a binding fiduciary duty to put their needs first to increase value for them. In its input-output models of corporate governance, inputs of shareholders, employees and suppliers are transformed into usable outputs that customers buy. This returns some capital benefit or profit to the corporation. Under this model, corporate decision makers only address the needs of those four parties: investors, employees, suppliers and customers, with an emphasis on investors' wishes. However, the stakeholder theory argues further that other parties are involved as well, including governmental bodies, political groups, trade associations, trade unions, 
communities, associated corporations, prospective employees, and prospective customers, the general public and perhaps even competitors.

The stakeholder view is an instrumental theory; since it integrates the resource-based view as well as the market-based view, and adds a new and expanding sociopolitical level which is taking root in the emergence of corporate social responsibilities. Effective communication with stakeholders is fundamental for successful implementation of social responsibility. Employees, in particular, are vital for changing companies' social or environmental performance especially in the construction industry. This presents an important area of potential synergy with safety and health at work where participation and dialogue with employees has long been recognized as an essential element for success (European Agency for Safety and Health at Work, 2004).

Research Methods and Procedures: The scope of the research is limited to the five most populous construction companies in Nigeria (Julius Berger Nigeria Plc, Setraco Nigeria Ltd, Fourgerolle Nigeria Ltd, Arab-Contractors Nigeria Ltd and Dantata\&Sawoe Nigeria Ltd). It is assumed that responses obtained from workers in these selected companies would be representative of all construction workers opinion on the implications of integrating safety and social responsibility in Nigerian construction companies. An exploratory, crosssectional survey was used in generating the primary data required for the study. The population of study consists of 40,568 workers of three categories $(3,560$ supervisors, 10,028 foremen and 26,980 workmen) drawn from the five construction companies selected for the study. A sample of 396 workers (35 supervisors, 98 foremen and 263 workmen) determined at $5 \%$ level of significance for sample error, using Taro Yamane's (1964) formula, was selected using stratified random sampling method for the purpose of questionnaire administration. The questionnaire was designed to obtain a fair representation of the opinions of the three categories of construction workers in the five selected companies using a five-point Likert type scale. The questionnaire responses of the sample respondents were presented using tables, analyzed and interpreted using simple percentages. A total of 396 copies of the questionnaire were administered, out of which 2 were cancelled while 4 were not returned and $390(98 \%)$ were used for analysis.

Table1, Response pattern on the extent integration of safety and social responsibility is dependent on the safety management system in the five selected construction companies

\begin{tabular}{|l|c|c|c|c|c|c|}
\hline $\begin{array}{l}\text { Category } \\
\text { Respondents/ } \\
\text { Workers }\end{array}$ & \multicolumn{5}{|c|}{ Responses Provided } \\
\cline { 2 - 7 } & $\begin{array}{c}\text { Very large } \\
\text { extent }\end{array}$ & Large extent & Mild extent & Poor extent & Very poor extent & Total \\
\hline Supervisors & 10 & 20 & 2 & 2 & 1 & 35 \\
\hline Foremen & 25 & 65 & 4 & 2 & 4 & 257 \\
\hline Workmen & 60 & 172 & 15 & 10 & 7 & 390 \\
\hline Total & 95 & 257 & 21 & & 4 & 7 \\
\hline
\end{tabular}

Source: Field Survey, 2011.

\section{RESULTS AND DISCUSSION}

Table 1, indicates that a total of 257 i.e. $66 \%$ of the workers across the three categories are of the opinion that integration of safety and social responsibility is to a large extent dependent on the safety management system in the five selected construction companies, 95 i.e. $24 \%$ of the workers are of the view that integration of safety and social responsibility is to a very large extent dependent on the safety management system, 21 workers i.e. $5 \%$ expressed a mild extent view of integration of safety and social responsibility dependent on the safety management system, 10 workers i.e. 3\% expressed a poor extent view while 7 workers i.e. $2 \%$ were of a very poor view. We therefore conclude that there is evidence that integration of safety and social responsibility is to a large extent dependent on the safety management system in the five selected construction companies as buttressed by the $66 \%$ large extent response rate of the sample respondents. 
Table2. Response pattern on the extent better corporate performance (improved productivity, good corporate governance, improved stakeholders' relations and reduced accident/incident rate) is dependent on the integration of safety and social responsibility in the five selected construction companies.

\begin{tabular}{|l|c|c|c|c|}
\hline Category of $\begin{array}{l}\text { Respondents } \\
\text { Respors }\end{array}$ & \multicolumn{4}{|c|}{ Responses Provided } \\
\cline { 2 - 5 } & $\begin{array}{c}\text { Large } \\
\text { extent }\end{array}$ & $\begin{array}{c}\text { Mild } \\
\text { extent }\end{array}$ & $\begin{array}{c}\text { Poor } \\
\text { extent }\end{array}$ & Total \\
\hline Supervisors & 20 & 10 & 5 & 35 \\
\hline Foremen & 75 & 15 & 8 & 98 \\
\hline Workmen & 230 & 20 & 7 & 257 \\
\hline Total & 325 & 45 & 20 & 390 \\
\hline
\end{tabular}

Source: Field Survey, 2011.

Table 2 shows that a total of 325 i.e.83.33\% of the workers across the three categories were of Table 3 Observed and Expected Frequencies of table 2 the view that better corporate performance (improved productivity, good corporate governance, improved stakeholders relations and reduced accident/incident rate) is to large extent dependent on the integration of safety and social responsibility in the five selected construction companies, 45 i.e. $11.54 \%$ of the workers expressed a mild extent view while 20 i.e. $5.13 \%$ of the workers expressed a poor extent view. We therefore conclude that there is evidence that better corporate performance (improved productivity, good corporate governance, improved stakeholders relations and reduced accident/incident rate)depends on integration of safety and social responsibility as buttressed by the $83.33 \%$ large extent response of the sample respondents.

\begin{tabular}{|l|c|c|c|c|}
\hline \multirow{2}{*}{$\begin{array}{l}\text { Category of } \\
\text { Respondents/Workers }\end{array}$} & \multicolumn{4}{|c|}{ Responses Provided } \\
\cline { 2 - 5 } & Large extent & Mild extent & Poor extent & Total \\
\hline Supervisors & $20(29.17)$ & $10(4.04)$ & $5(1.79)$ & 95 \\
\hline Foremen & $75(81.67)$ & $15(11.31)$ & $8(5.03)$ & $7(13.18)$ \\
\hline Workmen & $230(214.17)$ & $20(29.65)$ & 20 & 390 \\
\hline Total & 325 & 45 & 257 \\
\hline
\end{tabular}

Source: Field Survey, 2011.

\section{Test of Hypothesis}

(i) $\mathbf{H}_{\mathrm{o}}$ : Better corporate performance (improved productivity, good corporate governance, improved stakeholders relations and reduced accident/incident rate) is not dependent on the integration of safety and social responsibility in the five selected construction companies.

$\mathbf{H}_{1:} \quad$ Better corporate performance (improved productivity, good corporate governance, improved stakeholders relations and reduced accident/incident rate) is dependent on the integration of safety and social responsibility in the five selected construction companies.

(ii) $\alpha=0.05$

(iii) Degree of Freedom ( df $)=(r-1)(c-1=(3-1)(3-$ 1) $=4$

(iv)Chi- square critical value $x_{0.05}^{2}=9.49$

(v) ) Chi- square computed value from table 4 $=\mathrm{X}^{2}{ }_{1}=\sum\left(\mathrm{F}_{0}-\mathrm{Fe}\right)^{2} / \mathrm{Fe}$
Table 4 Computation of Chi-square Test Statistic from table 3

\begin{tabular}{|l|c|c|c|c|}
\hline Fo & Fe & $\begin{array}{c}\text { (Fo- } \\
\text { Fe) }\end{array}$ & (Fo-Fe) $^{2}$ & (Fo-Fe) $^{2} / F e$ \\
\hline 20 & 29.17 & 9.17 & 84.0889 & 2.8827 \\
\hline 75 & 81.67 & 6.67 & 44.4889 & 0.5447 \\
\hline 230 & 214.17 & -15.83 & 250.5889 & 1.1700 \\
\hline 10 & 4.04 & 5.96 & 35.5216 & 8.7925 \\
\hline 15 & 11.31 & 3.69 & 13.6161 & 1.2039 \\
\hline 20 & 29.65 & -9.65 & 93.1225 & 3.1407 \\
\hline 5 & 1.79 & 3.21 & 10.3041 & 5.7565 \\
\hline 8 & 5.03 & 2.97 & 8.8209 & 1.7537 \\
\hline 7 & 13.18 & -6.18 & 38.1924 & 2.8978 \\
\hline & & & & $\mathbf{x}^{2}=28.1425$ \\
\hline
\end{tabular}


Am. J. Soc. Mgmt. Sci., 2012, 3(1): 30-38

(vi) Decision Rule:

$$
\begin{aligned}
& \text { Reject } \mathrm{H}_{\mathrm{o}} \text { if } \mathrm{X}_{\mathrm{c}}{ }_{\mathrm{c}}>\mathrm{X}_{\mathrm{t}}^{2} \\
& \text { Accept } \mathrm{H}_{\mathrm{O}} \text { if } \mathrm{X}_{\mathrm{c}}{ }_{\mathrm{c}}<\mathrm{X}^{2}{ }_{\mathrm{t}}
\end{aligned}
$$

Since $\mathbf{X}^{2}{ }_{\mathrm{c}}>\mathbf{X}^{2}{ }_{\mathrm{t}}$ i.e. $28.1425>9.49$, we reject the null hypothesis and accept the alternative hypothesis that better corporate performance (improved productivity, good corporate governance, improved stakeholders relations and reduced accident/incident rate) is dependent on the integration of safety and social responsibility in the five selected construction companies.

\section{CONCLUSION}

This paper has tried to address the implications of integrating safety and social responsibility in selected construction companies in Nigeria from the stakeholder perspective.

Concisely stated, the main thrust of the stakeholder approach to integrating safety and social responsibility in construction activities at the company level is based on three principles:

- Effective communication with stakeholders is fundamental for successful integration of safety and social responsibility.

- Employees, in particular, are vital for changing companies' social or environmental performance especially in the construction industry.

- Better corporate performance will result in improved productivity, good corporate governance, improved stakeholders relations and reduced accident/incident rate.

\section{RECOMMENDATIONS}

Arising from the findings of this paper, it is suggested that the management of all construction companies in Nigeria should take the following measures:

Implement a systems approach to safety management that links safety and social responsibility in construction activities using ISO 26000 guidelines.

- Top management should be held accountable for corporate safety issues and communication of safety value to corporate stakeholders.

\section{REFERENCES}

Adams, S. (2003). The emerging management school of safety. Professional Safety, 48(9). European Agency for Safety and Health at Work. (2004). Corporate social responsibility and safety and health at work. Luxembourg.

Freeman, R. (1984). Strategic management: A stakeholder approach. Boston: Pitman.

Freeman, R., Harrison, J. \& Wicks, A. (2007). Managing for stakeholders. New Haven, CT: Yale University Press.

Hall, R. (2003). The implications of the Sarbanes-Oxley Act for the environmental health and safety auditing professional. Presentation at the Auditing Roundtable Legislative/Regulatory Interest Group spring meeting. Washington, DC: Crowell \& Moring.

International Organization of Standardization (ISO). (2010). Guidance on social responsibility [ISO/ FDIS 26000:2010(E)]. Geneva, Switzerland. 
Am. J. Soc. Mgmt. Sci., 2012, 3(1): 30-38

Manuele, F.A. (2003). On the practice of safety ( $3^{\text {rd }}$ ed.). Hoboken, NJ: John Wiley \& Sons.

Nestle. (2009). Creating shared value. Vevey, Switzerland: Author. Retrieved Nov. 10, 2010, from,www.nestle.com/Common/NestleDocuments/Doc uments/Library/Documents/

Corporate Social Responsibility/Nestle-CSV-Report-2009EN.pdf.

OSHA. (1989). Safety and health program management guidelines: Issuance of voluntary guidelines. Washington, DC: U.S. Department of Labor.

OSHA. (2002). Job hazard analysis (OSHA 3071).Washington, DC: U.S. Department of Labor.
Petersen, D. (2003). Techniques of safety management: A systems approach. Des Plaines, IL: ASSE.

Schneid, T. (2000). Modern safety and resource control management. New York: John Wiley \& Sons.

Schneid, T. (2008). Corporate safety compliance. Boca Raton, FL: CRC Press.

Verschoor, C. (2007). Ethics and compliance. Altamonte Springs, FL: IIA Research Foundation.

Werther, W. \& Chandler, D. (2006). Strategic corporate social responsibility. Thousand Oaks, CA: SAGE Publications.

Yamane, T. (1964) Statistics: An Introductory Analysis. $3^{\text {rd }}$ ed, New York. Harper and Row Publishers. 